
and Thrombosis

\title{
Isolation of Endogenous Anticoagulant N-Sulfated Glycosaminoglycans in Human Plasma from Healthy Subjects
}

\author{
Marco Ruggiero ${ }^{a}$ Michele Mellia Bruna Parma ${ }^{b}$ Pietro Bianchini ${ }^{b}$ \\ Simonetta Vannucchi a
}

a Department of Experimental Pathology and Oncology, University of Florence, and

bOpocrin Research Laboratories, Modena, Italy

\section{Key Words}

Heparin · Peptides · Human plasma • Anticoagulant activity $\cdot$ Hemostasis ciated in vitro with a variety of proteins and that this association could be responsible for modification of both heparin and protein activities.

Copyright $\odot$ 2002S. Karger AG, Basel

\begin{abstract}
Endogenous N-sulfated glycosaminoglycans (GAGs) comigrating with standard heparin and sensitive to nitrous acid treatment were isolated from plasma of healthy donors. The amount of these compounds was $7-10 \mu \mathrm{g} / \mathrm{ml}$, and activated partial thromboplastin time, anti-Xa and anti-lla activities were similar to those of standard heparin of high molecular mass. Analysis with gradient PAGE of the putative endogenous heparin showed a mean molecular mass of $12 \mathrm{kD}$. These $\mathrm{N}$-sulfated GAGs could be isolated only after removal of binding peptides that impaired purification by ion-exchange chromatography. We used SDS-PAGE as a tool to separate peptides from endogenous GAGs. N-sulfated GAGs exited the gel before peptides when the electrophoresis was overrun. Endogenous GAGs could be recovered by ion-exchange chromatography of the SDS-PAGE buffer, 'free' from associating peptides. These results strongly support the hypothesis that endogenous heparin is asso-
\end{abstract}

\section{Introduction}

The role of naturally occurring glycosaminoglycans (GAGs) in human blood has still to be elucidated. GAGs circulate in human plasma associated with a variety of other compounds, mostly proteins or peptides [1-3]. This association is poorly characterized and makes it quite difficult to extract and purify plasmatic GAGs. Among plasmatic GAGs, heparin is the most interesting one for its anticoagulant/antithrombotic properties, but it is also the most elusive one. Plasmatic heparin, together with heparin and heparan sulfate bound to endothelial cells, might play a physiological role in the maintenance of the hemostatic balance and might be involved in thrombotic/hemorrhagic pathologies [4-8]. The presence of heparin in human plasma was previously suggested, and all studies agree that heparin is associated with proteins or peptides [1, 9-11]. We previously demonstrated that when the

\begin{tabular}{ll}
\hline KARGER & ( 2002 S. Karger AG, Basel \\
Fax +4161306 1234 & 1424-8832/02/0321-0044\$18.50/0 \\
$\begin{array}{l}\text { E-Mail karger@karger.ch } \\
\text { www.karger.com }\end{array}$ & $\begin{array}{l}\text { Accessible online at: } \\
\text { www.karger.com/journals/pht }\end{array}$
\end{tabular}

S. Vannucchi

Dipartimento di Patologia e Oncologia Sperimentali

Viale Morgagni, 50

I-50134 Firenze (Italy)

Tel. +39055 42823, Fax +39055 4282333, E-Mail simonettavannucchi@yahoo.com 
supernatant of digested human plasma was submitted to sequential ethanol precipitation, the $60 \%$ fraction contained the greatest amount of plasmatic GAGs, and endogenous heparinase-sensitive material could be evidenced in gradient (24-30\%) PAGE [9].

In this study, we show that recovery and purification of endogenous N-sulfated GAGs, including heparin, from peptide complexes could be achieved by combining the resolving effect of electric field and molecular sieving of SDS-PAGE. Human N-sulfated GAGs were 'stripped' of 'masking' compounds and could be recovered 'free' from interacting peptides, comigrating with standard heparin and showing anticoagulant activity almost identical to that of standard heparin.

\section{Materials and Methods}

\section{Materials}

Heparin EP 756 (average molecular mass $12.9 \mathrm{kD}$ ) from bovine intestinal mucosa, low-molecular-mass heparin (batch 2123, average molecular mass $4.5 \mathrm{kD}$ ) and oligo-heparin (average molecular mass $2.1 \mathrm{kD}$ ) were from Opocrin Research Laboratories (Modena, Italy); the molecular and biological properties of standard heparins were previously described in detail by Bianchini et al. [12]. Trypsin (EC 3.4.21.4), chymotrypsin (EC 3.4.21.1), chondroitin sulfate A, chondroitinase AC (EC 4.2.2.5) and chondroitinase ABC (EC 4.2.2.4) were from Sigma Chem. Co. (St. Louis, Mo., USA). Papain (EC 3.4.22.2) was from Calibiochem (La Jolla, Calif., USA). Pepsin (EC 3.4.23.1) was from Boehringer Mannheim (Mannheim, Germany). Diethylaminoethyl (DEAE)-Sephacel was from Pharmacia (Uppsala, Sweden). Titan III Zip Zone cellulose acetate plates were from Helena Laboratories (Beaumont, Tex., USA). Azure A was from BDH (Poole, UK) and Alcian blue from Fisher Scientific Co. (Pittsburgh, Pa., USA). Reagents for SDS-PAGE were from Bio-Rad (Hercules, Calif., USA). Guanidine hydrochloride $(\mathrm{GdnHCl})$ and other common reagents were from Sigma.

\section{Preparation of the Fraction Containing GAGs from Human \\ Plasma}

All the experiments described thereafter were performed at least three times, each time starting with a different batch of human plasma collected from known healthy donors who had not received any heparin treatment for at least 1 year. Human plasma $(100 \mathrm{ml})$ from the local blood bank was submitted to proteolysis as described elsewhere [1]. Briefly, papain $(1 \mathrm{mg} / \mathrm{ml})$ was added for $24 \mathrm{~h}$ at $60^{\circ} \mathrm{C}$. The sample was then boiled and, at intervals of $24 \mathrm{~h}$, the following enzymes were added sequentially: trypsin, chymotrypsin, collagenase and pepsin, each at a final concentration of $1 \mathrm{mg} / \mathrm{ml}$. Each digestion was performed for $24 \mathrm{~h}$ at $37^{\circ} \mathrm{C}$. Samples were boiled before addition of each enzyme. After proteolysis, the sample was centrifuged at $15,000 \mathrm{~g}$ for $10 \mathrm{~min}$ and clear supernatant was stored at $-80^{\circ} \mathrm{C}$. The supernatant of digested plasma was precipitated with $66 \%$ ethanol. The pellet was solubilized in distilled water and dialyzed against $0.05 M$ Tris- $\mathrm{HCl}, \mathrm{pH}$ 7.4. Protein concentration was determined according to the method of Bradford [13].

\section{Ion-Exchange Chromatography}

Fractions obtained by $66 \%$ ethanol precipitation of the supernatant of digested human plasma or SDS-PAGE buffer (fig. 1) were applied to DEAE-Sephacel columns $(1 \times 3 \mathrm{~cm})$ equilibrated in $0.05 \mathrm{M}$ Tris- $\mathrm{HCl}, \mathrm{pH}$ 7.4. The columns were washed with $100 \mathrm{ml}$ of $0.1 \mathrm{M} \mathrm{NaCl}$ in the same buffer and then eluted in a stepwise manner with increasing concentrations of $\mathrm{GdnHCl}$ starting from $0.2 \mathrm{M}$.

\section{$P A G E$}

SDS-PAGE (15\% acrylamide) was performed according to the method of Laemmli [14] under reducing conditions (i.e. in the presence of $0.15 \%$ dithiothreitol). To begin with, $20 \mu \mathrm{l}$ of standard heparin $(1 \mathrm{mg} / \mathrm{ml})$ was loaded onto the gel in a lane distant from that where standard proteic molecular weight markers were loaded. After electrophoresis, the gel was cut vertically into two parts; the one containing the lane with molecular weight standards was stained with Coomassie brilliant blue as usual, while the one where heparin was loaded was rinsed two times for $10 \mathrm{~min}$ in distilled water in order to remove SDS, then stained with $0.08 \%(\mathrm{w} / \mathrm{v})$ azure A for $10 \mathrm{~min}$ and finally destained by frequent changes of distilled water. In this way, standard heparin appeared as a metachromatic spot migrating toward the bottom of the gel and eventually exited the gel if the electrophoresis was overrun. Thus, we could determine the length of time required for standard heparin to exit the gel. In other words, if the electrophoresis was overrun, the metachromatic spot corresponding to standard heparin could no longer be evidenced, while the proteic molecular weight markers, although slightly spread, were still there. It is worth noting that the metachromatic staining occurred only when heparin was present alone in the lane; the presence of peptides comigrating with heparin prevented the staining of heparin by azure A. Thus, when SDS-PAGE was used as a tool to separate endogenous N-sulfate GAGs from plasmatic peptides, the electrophoresis was run for a period of time significantly longer than that usually required to separate peptides. Typically, we performed six electrophoresis runs, each time loading $400 \mu \mathrm{g}$ of protein per slab, and using the same buffer, in order to accumulate enough GAGs. GAGs from SDSPAGE buffer were then isolated by ion-exchange chromatography as described above, and evidence by cellulose acetate electrophoresis. Gradient (24-30\%) PAGE was performed according to the method of Lyon and Gallagher [15].

\section{Cellulose Acetate Electrophoresis}

Cellulose acetate electrophoresis was performed on fractions eluted from DEAE-Sephacel columns following the protocol described in figure 1 (procedures a and b). The fractions eluted from DEAE-Sephacel columns were lyophilized, resuspended in distilled water in order to reach a $4 \mathrm{M}$ concentration fo $\mathrm{GdnHCl}$ and precipitated with 2 volumes of absolute ethanol. The precipitated fractions were solubilized in appropriate amounts of distilled water, and $2 \mu \mathrm{l}$ were analyzed by electrophoresis on cellulose acetate at $\mathrm{pH} 1.0$ [8]. Nitrous acid treatment was performed according to the procedure described by Cappelletti et al. [16]. Enzymatic treatments with chondroitinase $\mathrm{AC}$ or chondroitinase $\mathrm{ABC}$ were performed as described elsewhere [17]. After electrophoresis on cellulose acetate at $\mathrm{pH}$ 1.0, the sheets were stained in an aqueous solution of $0.1 \%$ Alcian blue, destained in $1 \%$ acetic acid, rinsed under running water and dried.

\section{Analysis of Anticoagulant Activities}

Conventional tests were performed on fractions eluted from ion exchanger following the protocol described in figure 1: anti-Xa [18], 


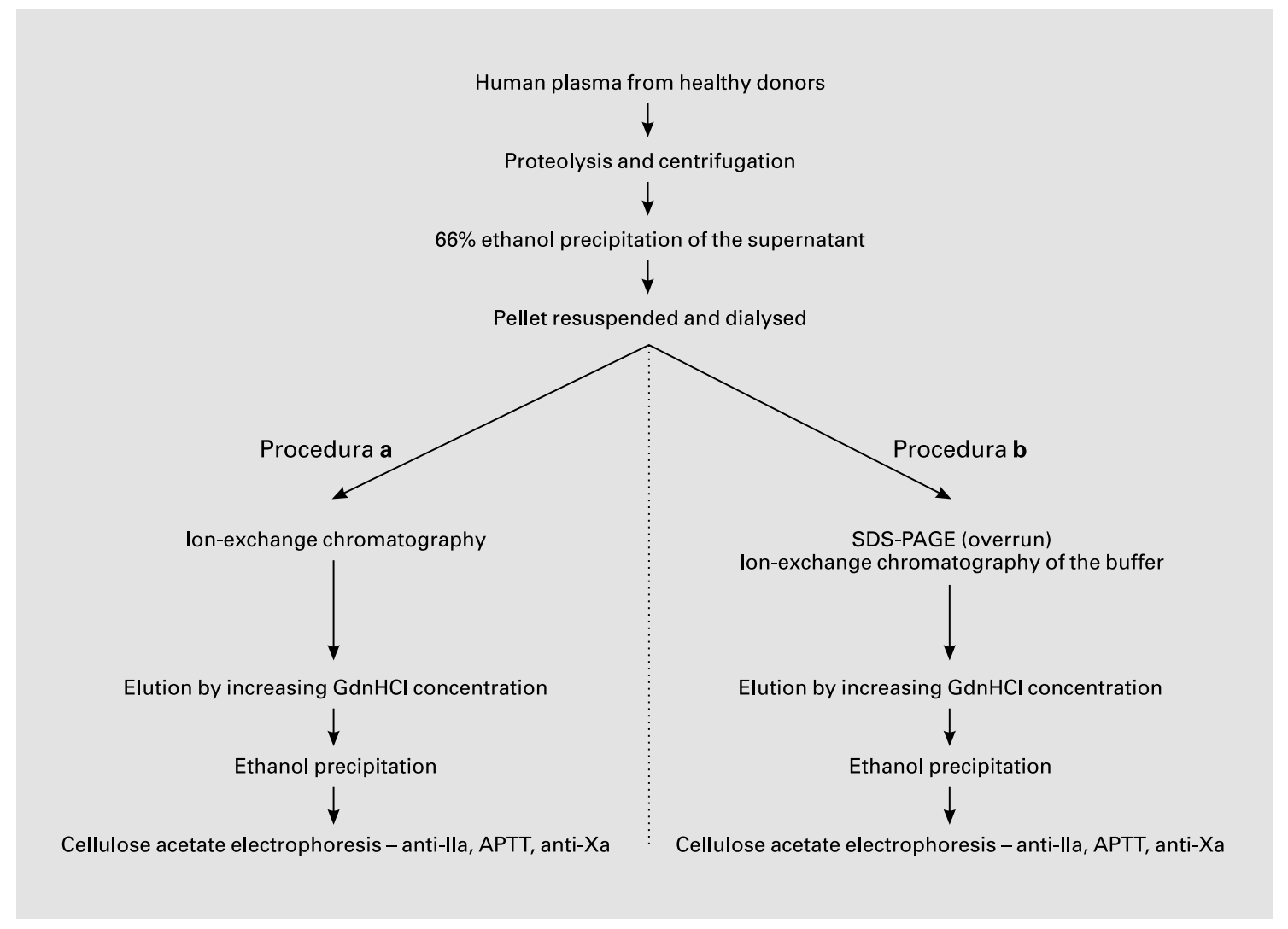

Fig. 1. Scheme of the analytical protocol.

activated partial thromboplastin time (APTT) [19] and anti-IIa [20]. The activity was expressed as units $/ \mathrm{ml}$.

A scheme of the analytical protocol is presented in figure 1.

\section{Results}

We performed complete proteolysis of human plasma; as previously demonstrated, this procedure, followed by centrifugation at $15,000 \mathrm{~g}$ for $10 \mathrm{~min}$, released $100 \%$ of the sulfated GAGs in the supernatant [1]. These GAGs, including heparinase-sensitive material (endogenous heparin?), were precipitated by ethanol together with peptides that impaired migration of standard GAGs in cellulose acetate electrophoresis [9]. Thus, the supernatant of digested plasma was always treated with 2 volumes of absolute ethanol (final concentration 66\%) in order to obtain the bulk of endogenous heparin together with heparin-binding compounds. Precipitation with $66 \%$ ethanol, followed by exhaustive dialysis, reduced the protein content of the supernatant of the digested plasma sample from 0.66 to $0.18 \mathrm{mg} / \mathrm{ml}$.

As a first attempt to isolate endogenous GAGs, the fraction from $66 \%$ ethanol precipitation was submitted to chromatography on a DEAE-Sephacel column and eluted with increasing $\mathrm{GdnHCl}$ concentrations (fig. 1); eluted fractions were analyzed with cellulose acetate electrophoresis (fig. 2). Figure 2 shows that no Alcian blue-positive material comigrating with standard heparin was recognizable. No anticoagulant activity was detected in fractions eluted from ion exchanger. Figure 2 also shows Alcian blue-positive bands comigrating with or migrating slower than chondroitin sulfate $\mathrm{A}$. This material was insensitive to nitrous acid, but was sensitive to chondroitinase AC and chondroitinase $\mathrm{ABC}$ (not shown). These bands represent chondroitin sulfate with different degree of sulfation, i.e. compounds that have been described among plasmatic GAGs [21, 22].

The experiments shown in figure 2 demonstrated that ion-exchange chromatography alone was unsuitable to 


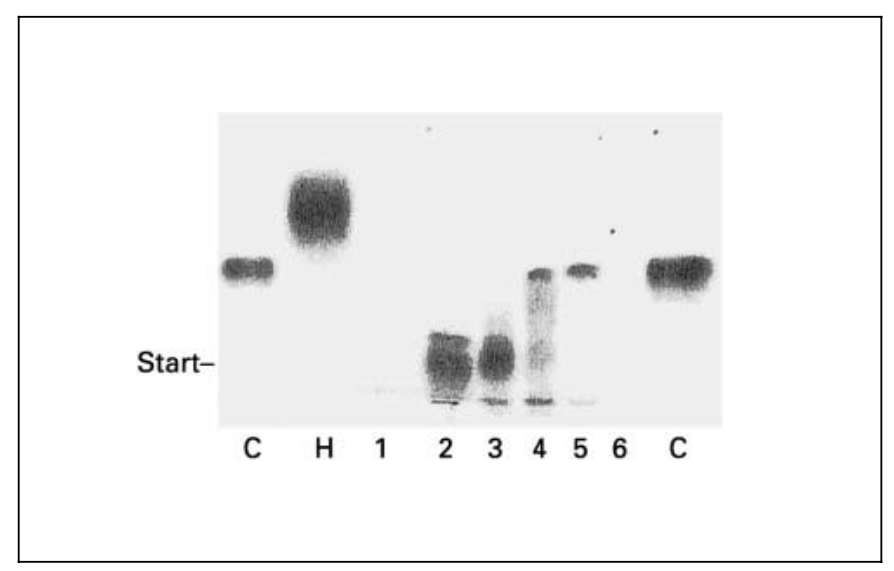

Fig. 2. Analysis of the fractions obtained by ion-exchange chromatography (procedure a) by cellulose acetate electrophoresis at $\mathrm{pH} 1.0$. Fractions were eluted from DEAE-Sephacel columns at 0.2 (lane 1), 0.3 (lane 2), 0.4 (lane 3), 0.6 (lane 4), 1.0 (lane 5) and 2.0 M (lane 6) $\mathrm{GdnHCl} .2 \mu \mathrm{l}$ of an aqueous solution of heparin, oligo-heparin and chondroitin sulfate A at a concentration of $200 \mu \mathrm{g} / \mathrm{ml}$ were used as standard. The precipitated fractions obtained by ion-exchange chromatography were solubilized in distilled water and $2 \mu \mathrm{l}$ were submitted to electrophoresis on cellulose acetate at $\mathrm{pH}$ 1.0. This aliquot $(2 \mu \mathrm{l})$ was the equivalent of $1.0 \mathrm{ml}$ of the starting plasma sample. Thus, the amount of plasmatic GAGs isolated by ion-exchange chromatography of the supernatant of digested plasma, calculated by densitometric comparison with standard molecules, was $1.0 \mu \mathrm{g} / \mathrm{ml} . \mathrm{H}=$ Heparin $(12.9 \mathrm{kD}) ; \mathrm{C}=$ chondroitin sulfate $\mathrm{A}$.

separate plasmatic N-sulfated GAGs endowed with anticoagulant activity from the binding peptides. Assuming that formation of GAG-peptide complexes was responsible for this failure, we used SDS-PAGE as a tool to entrap peptides and separate endogenous $\mathrm{N}$-sulfated GAGs (fig. 1). Figure 3 demonstrates that standard heparin migrated toward the bottom of the gel in SDS-PAGE $(15 \%)$ and could be evidenced using the staining procedure described in Materials and Methods. Thus, an aliquot of the $66 \%$ ethanol precipitate, after dialysis and concentration, was loaded onto the gel for SDS-PAGE. The electrophoresis was overrun as described in Materials and Methods. The buffer containing the material thus recovered from the gel was then submitted to ion-exchange chromatography on DEAE-Sephacel columns, and the eluted fractions, after dialysis, concentration and precipitation with ethanol, were analyzed with cellulose acetate electrophoresis (fig. 4). Figure 4 shows that after these experimental steps, in the fractions eluted at $0.4,1.0$ and $2.0 \mathrm{M}$ $\mathrm{GdnHCl}$, there were endogenous N-sulfated GAGs evidenced as Alcian blue-positive material comigrating with

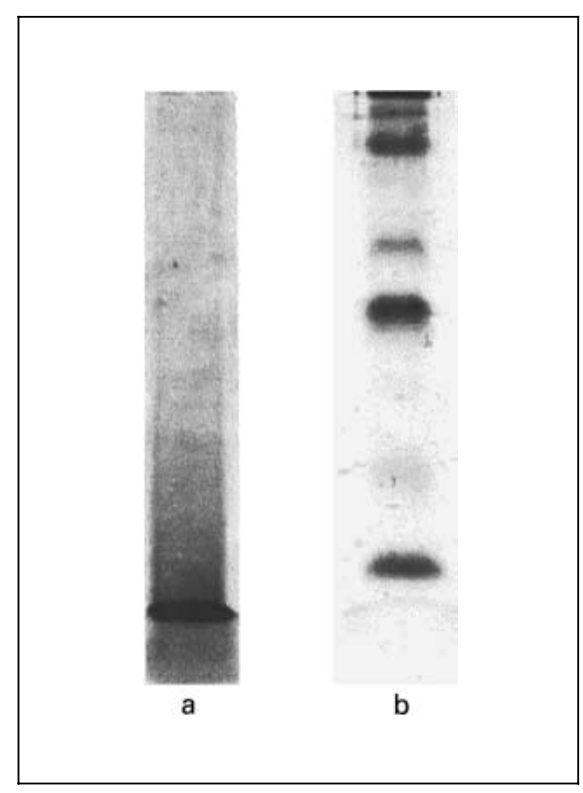

Fig. 3. SDS-PAGE (15\%) of standard heparin. Standard heparin (lane a) was run in SDS-PAGE (15\%) and stained with azure A after removing SDS as described in Materials and Methods. Lane b shows the position of the proteic molecular markers stained by Coomassie brilliant blue in the same running gel.

standard heparin (fig. 4A) and sensitive to nitrous acid treatment (fig. 4B). The bulk of N-sulfated GAGs was recovered in the $1.0 \mathrm{M} \mathrm{GdnHCl}$ fraction. The amount of material eluted in all the fractions could be calculated as $7-10 \mu \mathrm{g} / \mathrm{ml}$ of the starting plasma sample by densitometric comparison with the known amount of standard heparin. Anticoagulant activity of these fractions was assayed in vitro by different tests: anti-Xa, anti-IIa and APTT (table 1). The bulk of anti-Xa, anti-IIa and APTT activity was present in the fraction eluted with $1.0 \mathrm{M} \mathrm{GdnHCl}$. Anticoagulant activity of the fraction eluted with $1.0 \mathrm{M}$ $\mathrm{GdnHCl}$ was as follows: anti-Xa $256.2 \pm 34.8$ units $/ \mathrm{ml}$; anti-IIa $262.8 \pm 29.1$ units/ml; APTT $265.5 \pm 18.1$ units $/ \mathrm{ml}$. The ratio of anti-Xa to anti-IIa was quite similar to that of standard heparin of high molecular mass [12, 23]. The fraction eluted at $1.0 \mathrm{M} \mathrm{GdnHCl}$, when submitted to gradient PAGE, evidenced a metachromatic spot of approximate mean molecular mass of $12 \mathrm{kD}$ on the basis of comparison with standard heparin of known molecular mass (fig. 5). 

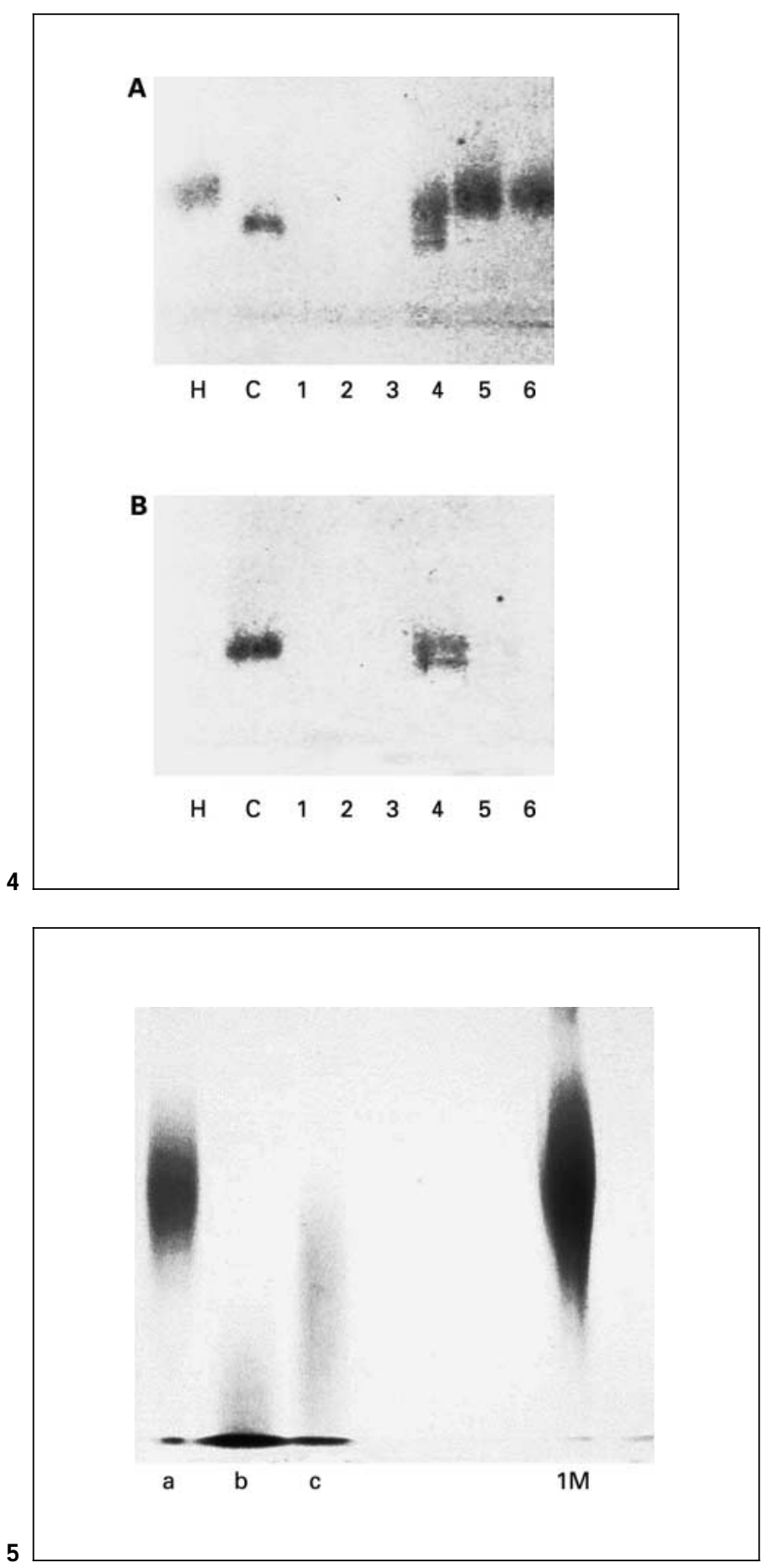

\section{Discussion}

In this study, we describe the isolation and recovery of circulating N-sulfated GAGs from plasma of healthy subjects. The amount of $\mathrm{N}$-sulfated GAGs endowed with
Table 1. Anticoagulant activity of fractions obtained by ionexchange chromatography using two different procedures

\begin{tabular}{llll}
\hline $\begin{array}{l}\text { Fractions eluted } \\
\text { at a GdnHCl } \\
\text { molarity of }\end{array}$ & $\begin{array}{l}\text { Anti-Xa } \\
\text { units/ml }\end{array}$ & $\begin{array}{l}\text { Anti-IIa } \\
\text { units/ml }\end{array}$ & $\begin{array}{l}\text { APTT } \\
\text { units/ml }\end{array}$ \\
\hline $\begin{array}{l}\text { Procedure a } \\
0.2\end{array}$ & $<1$ & $<1$ & \\
0.3 & $<1$ & $<1$ & $<1$ \\
0.4 & $<1$ & $<1$ & $<1$ \\
0.6 & $<1$ & $<1$ & $<1$ \\
0.6 & $<1$ & $<1$ & $<1$ \\
1.0 & $<1$ & $<1$ & $<1$ \\
2.0 & $<1$ & $<1$ & $<1$ \\
\hline Procedure b & & & $<1$ \\
0.2 & $<1$ & $<1$ & $<1$ \\
0.3 & $<1$ & $<1$ & $<1$ \\
0.4 & $<1$ & $<1$ & $6.8 \pm 2.1$ \\
0.6 & $6.4 \pm 1.1$ & $7.0 \pm 2.7$ & $265.5 \pm 18.1$ \\
1.0 & $256.2 \pm 34.8$ & $262.8 \pm 29.1$ & $18.3 \pm 2.1$ \\
2.0 & $16.8 \pm 2.7$ & $24.0 \pm 2.1$ & \\
\hline
\end{tabular}

Fig. 4. Analysis of the fractions obtained by ion-exchange chromatography of SDS-PAGE buffer (procedure b) by cellulose acetate electrophoresis at $\mathrm{pH}$ 1.0. A Fractions eluted from DEAE-Sephacel columns at 0.2 (lane 1), 0.3 (lane 2), 0.4 (lane 3), 0.6 (lane 4), 1.0 (lane 5) and 2.0 $M$ (lane 6) $\mathrm{GdnHCl}$. B The same fractions treated with nitrous acid. $2 \mu \mathrm{l}$ of an aqueous solution of heparin and chondroitin sulfate $A$ at a concentration of $200 \mu \mathrm{g} / \mathrm{ml}$ were used as standard. The precipitated fractions were solubilized in distilled water and $2 \mu \mathrm{l}$ were submitted to electrophoresis on cellulose acetate at $\mathrm{pH}$ 1.0. This aliquot $(2 \mu \mathrm{l})$ was the equivalent of $1 \mathrm{ml}$ of the starting plasma sample in fractions eluted at $0.2,0.3,0.4,0.6$ and $2.0 \mathrm{M} \mathrm{GdnHCl}$ and of $0.1 \mathrm{ml}$ in the fraction eluted at $1.0 \mathrm{M} \mathrm{GdnHCl}$. Thus, the amount of nitrous acid-sensitive material isolated by ion-exchange chromatography of the SDS-PAGE eluting buffer, calculated by densitometric comparison with standard molecules, was about $7-10 \mu \mathrm{g} / \mathrm{ml}$ of human plasma. $\mathrm{H}=$ Heparin $(12.9 \mathrm{kD}) ; \mathrm{C}=$ chondroitin sulfate $\mathrm{A}$.

Fig. 5. Gradient (24-30\%) PAGE of standard heparins of different molecular mass and of the sample eluted at $1.0 \mathrm{M} \mathrm{GdnHCl}$. Lane a: standard heparin EP 756, average molecular mass $12.9 \mathrm{kD}$; lane b: standard heparin-derived oligosaccharides, average molecular mass $2.1 \mathrm{kD}$; lane c: standard heparin of low molecular mass, average molecular mass $4.5 \mathrm{kD}$; lane $1 \mathrm{M}$ : fraction eluted at $1 \mathrm{M} \mathrm{GdnHCl}$ from ion-exchange chromatography.

anticoagulant activity was significant; thus, considering that much lower amounts of exogenous heparin would render blood uncoagulable, it is conceivable that circulating N-sulfated GAGs were associated with other endogenous compounds, such as peptides. Among the recovered 
endogenous GAGs, an N-sulfated GAG species comigrating with standard heparin, endowed with significant anticoagulant activity and sensitive to nitrous acid treatment was recognizable. The pattern of anticoagulant activity of this N-sulfated GAG species was indistinguishable from that of standard heparins [12, 23].

The presence of endogenous circulating GAGs with anticoagulant activity has been discussed for a long time. In rare pathological conditions, heparan sulfate and heparin-like molecules have been described as responsible for bleeding disorders $[6,24,25]$. However, the presence of 'real' heparin in plasma of healthy subjects is still a matter of discussion [11,22]. In this study, thanks to the sequential application of different separation techniques (fig. 1), we demonstrated that an N-sulfated GAG species show- ing all the anticoagulant features of 'real' heparin could be recovered from normal human plasma. We hypothesize that under normal conditions, endogenous binding compounds, such as proteolysis-resistant peptides, associate with these GAGs and mask or modulate their availability. It will be interesting to determine whether and how circulating anticoagulant GAGs are released from association with these compounds, and how these activities are regulated in normal and pathological conditions.

\section{Acknowledgement}

This work was supported by grants from the University of Florence, Italy.

\section{References}

1 Pasquali F, Oldani C, Ruggiero M, Magnelli L, Chiarugi V, Vannucchi S: Interaction between endogenous circulating sulfated-glycosaminoglycans and plasma proteins. Clin Chim Acta 1990;192:19-27.

2 Calatroni A, Vinci R, Ferlazzo AM: Characteristics of the interactions between acid glycosaminoglycans and proteins in normal human plasma as revealed by the behaviour of the protein-polysaccharide complexes in ultrafiltration and chromatographic procedures. Clin Chim Acta 1992;206:167-180.

3 Cherchi GM, Formato M, Demuro P, Masserini M, Varani I, DeLuca G: Modifications of low density lipoprotein induced by the interaction with human plasma glycosaminoglycanprotein complexes. Biochim Biophys Acta 1994;1212:342-352.

4 Vannucchi S, Fibbi G, Pasquali F, Del Rosso M, Cappelletti R, Chiarugi V: Adhesion-dependent heparin production by platelets. Nature 1982;296:352-353.

5 Masson PJ, Coup D, Millet J, Brown NL: The effect of the beta-D-xyloside naroparcil on circulating plasma glycosaminoglycans. An explanation for its known antithrombotic activity in the rabbit. J Biol Chem 1995;270:2662-2668.

6 Palmer RN, Rick ME, Rick PD, Zeller JA, Gralnick MD: Circulating heparan sulfate anticoagulant in a patient with a fatal bleeding disorder. N Engl J Med 1984;310:1696-1699.

7 Shworak NW, Shirakawa M, Colliec-Jouault S, Liu J, Mulligan RC, Birinyi LK, Rosenberg RD: Pathway-specific regulation of the synthesis of anticoagulantly active heparan sulfate. $\mathrm{J}$ Biol Chem 1994;269:24941-24952.

8 Cavari S, Vannucchi S: Glycosaminoglycans exposed on the endothelial cell surface. Binding of heparin-like molecules derived from serum. FEBS Lett 1993;323:155-158.
9 Cavari S, Vannucchi S: Detection of heparinlike glycosaminoglycans in normal human plasma by polyacrylamide-gel electrophoresis. Clin Chim Acta 1996;252:159-170.

10 Snow AD, Kisilevsky R, Stephens C, Anastassiades T: Electrophoresis of glycosaminoglycans isolated from normal human plasma. Direct evidence for the presence of a heparin-like molecule. Biomed Biochim Acta 1987;46:537546.

11 Volpi N, Cusmano M, Venturelli T: Qualitative and quantitative studies of heparin and chondroitin sulfates in normal human plasma. Biochim Biophys Acta 1995;1243:49-58.

12 Bianchini P, Bergonzini GL, Parma B, Osima B: Relationship between plasma antifactor Xa activity and the antithrombotic activity of heparins of different molecular mass. Haemostasis 1995;25:288-298.

13 Bradford MM: A rapid and sensitive method for quantitation of microgram quantities of protein utilizing the principle of protein-dye binding. Anal Biochem 1976:72:248-254.

14 Laemmli UK: Cleavage of structural proteins during the assembly of the head of bacteriophage T4. Nature 1970;227:680-685.

15 Lyon M, Gallagher JT: A general method for the detection and mapping of submicrogram quantities of glycosaminoglycan oligosaccharides on polyacrylamide gels by sequential staining with azure A and ammoniacal silver. Anal Biochem 1990;185:63-70.

16 Cappelletti R, Del Rosso M, Chiarugi V: A new method for characterization of N-sulfated glycosaminoglycans by a rapid and multisample nitrous acid treatment during an electrophoretic run and its application of the analysis of biological samples. Anal Biochem 1980;105:430435 .
17 Cavari S, Stramaccia L, Vannucchi S: Endogenous heparinase-sensitive anticoagulant activity in human plasma. Thromb Res 1992;67: 157-165.

18 Teien AN, Lie M, Abildgaard U: Assay of heparin in plasma using a chromogenic substrate for activated factor X. Thromb Res Suppl 1976;8: 413-416.

19 Basu D, Gallus A, Hirsh J, Cade J: A prospective study of the value of monitoring heparin treatment with activated partial thromboplastin time. N Engl J Med 1972;287:324-327.

20 Handeland GF, Abildgaard U: Assay of unfractionated and LMW heparin with chromogenic substrates: Twin methods with factor $\mathrm{Xa}$ and thrombin. Thromb Res Suppl 1984;35:627636.

21 Hata RI, Ohakawa SI, Nagai Y: Low-sulfated chondroitin sulfate in human blood and urine. Biochim Biophys Acta 1978;543:156-166.

22 Staprans I, Felts JM: Isolation and characterization of glycosaminoglycans in human plasma. J Clin Invest 1985;76:1984-1991.

23 Chevanne M, Caldini R, Manao G, Ruggiero M, Vannucchi S: Heparin binding peptides copurify with glycosaminoglycans from human plasma. FEBS Lett 1999;463:121-124.

24 Horne MK 3rd, Chao ES, Wilson OJ, Scialla SJ, Lynch MA, Kragel PJJ: A heparin-like anticoagulant as part of global abnormalities of plasma glycosaminoglycans in a patient with transitional cell carcinoma. J Lab Clin Med 1991;118:250-260.

25 Bussel JB, Steinherz PG, Miller DR, Hilgartner MW: A heparin-like anticoagulant in an 8month-old boy with acute monoblastic leukemia. Am J Pathol 1984;16:83-90. 